\title{
(Custodial) spaces to grow? Adolescent development during custodial transitions
}

\section{Jayne Price and Jennifer Turner}

\section{Abstract}

Drawing on empirical data from two individual research projects, this paper extends the literature of child and youth incarceration and offers a previously unexplored analysis of experiences and transitions through institutional environments for young people. Different penal environments have different operational practices and treatment according to arbitrary age-determined constructions of childhood, youth and young adulthood, evidenced by decreasing safeguards. This article demonstrates the reduction of operative and supportive investment in those held, and the shifting perception from children that require 'training' to young people and young adults who are managed and whose particular needs are neglected. The arbitrary nature of transitions presents a paradox between developmental maturity as an individualistic ongoing process and arbitrary age-determined transitions. As such, it is argued that there should be a more developmental approach to caring for young people across penal environments which accounts for their ongoing maturity and complex needs.

\section{Introduction}

The age of majority (when an individual is legally considered an adult) is 18 years in England and Wales. Rights, responsibilities, employment and access to institutions are statutorily assigned and accrued through the life-course by policies subject to age parameters (Wyn and White, 1997). Key milestones - such as leaving home, starting an occupation and getting married - tend to take place much later now than they did for previous generations (Dünkel, 2015) and far beyond the acquisition of adult status at aged 18 years (Roberts, 2009). Young people no longer follow these 'socially expected and culturally transmitted age-norms' (Heinz, 2009: 3), which are believed to construct societal transitions between childhood and adulthood. In addition, the relations and divisions within social structures means that the processes of growing up are thought to be experienced differently and shaped by the relations of class, ethnicity and gender (Goldson, 2013). There is also growing evidence that maturity, sensitive neurological changes and stability does not map directly onto legal structures, extending up to age 25 years. Cognitive, behavioural and emotional capacities continue to evolve beyond the age of 18 years and do so at differing rates. As a result, young adults often have more sensitive responses to social and emotional stimulus than older adults and therefore respond to situations differently. Their ongoing neurological developmental and maturation impact numerous attributes including decision making, behaviour 
and ability to reason (Bryan-Hancock and Casey, 2011; Edwards, 2009; Sawyer et al., 2018; Tanner and Arnett, 2009).

Whilst the body of literature regarding transitions into adulthood generally acknowledges that such societal and developmental transitions extend beyond the acquisition of the legal status of adulthood, transitions between institutional spaces have been criticised for remaining arbitrarily determined by age. For those young people incarcerated throughout their development from childhood to adulthood, this personal 'transition' is marked by experiences of a journey through a variety of different justice spaces whereby their age dictates transfer to a different institution. There is a multitude of institutions that may house various different age groups (10-18, 12-18, 15-18, 1821, and 18 and over). The transition is more pronounced for young females, who, being fewer in their numbers across the prison estate, have far fewer options for custody and are often housed alongside adult prisoners from a much earlier age (Elwood, 2013; MoJ, 2015a). Institutional transitions are fraught with difficulty (Hughes and Strong, 2016) and a number of independent reviews have highlighted their detrimental impacts upon young people during periods of developmental maturity. Often, owing to limited resources and staff training, institutions are unable to facilitate the supportive networks that engender the more rehabilitative environment that is intended within the juvenile secure estate (Harris, 2015; HMI of Prisons and HMI of Probation, 2019).

Each institution provides different accommodation and regime provisions, which can significantly impact the lived experience of that environment and generates a different set of expectations of child- and adulthood. Whilst much academic research considers child and youth imprisonment (see for example Goldson, 2002, 2015; Gooch, 2019), there is a dearth of research that explores the transitions through a multitude of carceral spaces at a crucial stage of identify formation and neurological development. This article explores this by drawing on qualitative interviews with children and young people in the juvenile secure estate and young adult/adult estate. Here we present findings from, first, Secure Training Centres [STCs] and then Young Offenders Institutions [YOIs] and young adult/adult institutions in turn to stimulate a vital discussion that interrogates the custodial journey in conjunction with transitions from childhood to adulthood. In doing so, we highlight the need for a developmental approach to caring for young people across penal environments that accounts for their ongoing maturity and complex 
needs. Before presenting our empirical material, we first provide some context to the juvenile secure state in England and Wales before introducing our methodological approach.

\section{The juvenile secure estate}

Since the first purpose-built institution to incarcerate children and young people opened at Parkhurst prison in 1838, a variety of institutions and penal regimes exclusively for this population have existed in England and Wales. As Goldson highlights, although the 'descriptors' of each facility has varied, 'the practice of child incarceration has remained constant' (2005: 79). At the time of writing, custodial provision in England and Wales for those aged under 18 years is the responsibility of the Youth Custody Service, a distinct arm of Her Majesty's Prison and Probation Service (HMPPS) (formally the National Offender Management Service [NOMS]). There are three types of institutions within the juvenile secure estate. Eight local authority Secure Children's Homes (SCHs) can hold children and young people aged 10-18 years. Privately managed STCs hold children and young people aged between 12 and 18 years. Both of these smaller units are intended to provide educational and tailored support for the particular needs and vulnerabilities of those held (Department for Education, 2020; Warner et al., 2018). Accordingly, they are the most expensive custodial placements at an average of $£ 273,000$ per annum for an SCH and $£ 212,000$ in an STC (Falola, 2020). The majority of the male, under 18 custodial population is held in five YOIs. The difference in the level of care is evidenced by the investment in resources, with lower staff ratios and an average annual cost of $£ 120,000$ per place (Falola, 2020). Ongoing plans for 'new' secure schools are controversial (see Hart, 2017).

Whilst it is clear from their long history that such institutions have been 'omnipresent', their use has fluctuated over time (Goldson, 2015: 171). The significant 70\% drop in custodial numbers over the past 10 years (YJB, 2020a) in the context of austerity and diversion has been an 'unexpected, though broadly welcomed development' (Bateman, 2012: 38) and resulted in the Youth Justice Board (YJB) - who were then responsible for the juvenile secure estate decommissioning more than 1,000 places from February 2010 (National Audit Office, 2010; YJB, 2011). However, what has not diminished over time is the concern about the suitability of these institutions for children and young people (Goldson, 2002, 2015; Willow, 2015; Gooch, 2015, 2016). The quality of provision across the juvenile secure estate has been disputed (Wood et al, 2017) and the oversight 'culture' of 'containment and control' (Independent Inquiry Child Sexual 
Abuse, 2019: vi) has also been criticised. There have been a number of recent controversies including allegations of staff abuse (Panorama, 2016) and neglect across STCs (Article39.org.uk, 2020). Damming YOI inspection reports repeated issues that appear to have persisted for two decades. In 2017, HM Chief Inspector of Prisons concluded that 'there was not a single establishment [STC and YOI] that [they] inspected in England and Wales in which it was safe to hold children and young people' (2017: 9), which led to the Chief Inspector of Prisons triggering an urgent notification for response from the Secretary of State(Clarke, 2019).

Incarcerated young people are routinely drawn from some of the most sociallydisadvantaged circumstances and have a number of complex support needs. In the majority, they have experienced a variety of 'distressing' or 'alienating' factors (Goldson, 2005: 80) such as poverty; family dysfunction; substance abuse; emotional, physical and sexual abuse; self-harm; homelessness; and reduced employment or educational opportunities prior to their incarceration (Kroll et al, 2002: 1977). It is therefore no surprise that, in 2017/18, 32\% of boys across YOIs reported having an emotional or mental health problem (Green, 2019). Those held are said to have 'higher concentrations of complex needs' (Bateman, 2015: 4) and are extremely vulnerable (Hart, 2017). And, it is often argued that penal custody is 'not equipped' to meet these particular needs (HMI of Prisons, 2000: 69-70). In addition to their disadvantaged profile prior to incarceration, it is critical to note that the custodial environment tends to stall maturation and 'risks exposing children to very real damage and harm, even fatal harm, during their formative years' (Gooch, 2016: 278). For young adults, their complex and ongoing development combined with their oftentraumatic circumstances prior to entering prison has numerous impacts upon behaviour and engagement with services and interventions (Harris, 2015; NOMS, 2015). Despite vulnerability extending beyond age 18 years (Bateman, 2015) there is no such focus on safeguarding this group as there are with children. Poor conditions within establishments holding young adults compounds issues, contributes to violence and negative outcomes for this population (HM Chief Inspector of Prisons, 2015; House of Commons Justice Committee, 2016).

The detrimental experience of imprisonment for young people is exacerbated during transitions. This period has been acknowledged as 'stressful' (Harris, 2015) and a time of increased vulnerability (NOMS, 2012). Additionally, despite the decline in population, the number of those expected to transition into the young adult/adult estate has remained constant at nearly $40 \%$ rising 
to $48 \%$ in $2018 / 19$ (YJB, 2020b). Previously-designated young adult YOIs (intended for those aged 18-21 years), are said to be 'coterminous' with adult prisons (National Preventative Mechanism, 2018: 51). Since they are increasingly accommodating older adult prisoners (HM Chief Inspector of Prisons, 2015) these institutions are thus merging into the adult estate. Although guidance has recently been issued (YJB, 2018) there is less work that focuses on these transitions through custodial spaces - from the learning environment of the STC through to the young adult/adult estate. Taking such a lead, we can report findings that specifically attend to the complex needs of such a cohort of prisoners and seek to inform future transitions practices. In the following section, we outline our methodology before presenting findings that explore the transition through custodial spaces for detainees whose sentence sees them age from 'children' to 'adults'.

\section{Methods and case studies}

This paper combines interview data from children and young people within STCs, YOIs and young adult/adult institutions from two individual research projects to enable a vital exploration of the experience of imprisonment through childhood, youth and young adulthood, and the movement between institutions and the different environments. Although it is acknowledged that a small number of young people transition from SCHs into the juvenile and adult penal estate, due to practical and ethical issues of accessing these institutions their experiences are not captured here (please see NPM (2018)). In the first research project, one-to-one interviews were held on one occasion with staff members $(n=9)$ and young people $(n=9)$ in one STC. Four young people were also involved in a focus group and associated design activity at the same facility. ${ }^{1}$ The destination of these children (progression to another institution or release into the community) was unknown. In this research project, the overarching aims were to explore the lived experiences of the STC as an architectural space for those living and working there. This data is combined with that from the

\footnotetext{
${ }^{1}$ Jennifer Turner's empirical data presented in this paper was funded by an ESRC Impact Acceleration Award 'Therapeutic Environments for Youth Custody' at the University of Birmingham, for which Dominique Moran was PI. This was in conjunction with an ESRCfunded comparative project in the UK and Nordic region in 2015/16 investigating how penal aims and philosophies (that is, what prison is 'for') are expressed in design of new prisons (completed in or after 2010); and how those prisons are experienced by prisoners and staff. ESRC Standard Grant ES/K011081/1: 01/01/2014-30/06/2017, “Fear-suffused environments" or potential to rehabilitate? Prison architecture, design and technology and the lived experience of carceral spaces'. The PI was Yvonne Jewkes and Co-I was Dominique Moran. The data is used here with the agreement of and thanks to Moran and Jewkes.
} 
second research project which uniquely 'tracked' young people as they progressed through institutions. Interviews were conducted with young people due to transfer into another institution $(n=14)$ on two occasions: 'pre'-transition within a YOI aged 17 years and 'post'-transition within a young adult/adult prison aged 18 years $^{2,3}$. These interviews took place across two YOIs and four young adult/adult institutions. Semi-structured interviews were also undertaken with selected stakeholders $(n=22)$ who were involved with, or who had expert knowledge of, juvenile and young adult/adult penal detention; including academics $(n=3)$, charity workers $(n=2)$, inspectors from independent inspectorates $(n=2)$, lawyers $(n=1)$, civil servants $(n=2)$ and personnel from YOI $(n=5)$ and young adult/adult institutions $(\mathrm{n}=7)$. This research explored how young people comprehended and experienced transitions between juvenile YOIs and young adult/adult institutions from the perspectives of young people and stakeholders. The young people were asked about their experiences within the institution they were currently held, how they were prepared for and negotiated their transitions and stakeholders were also asked for their perspectives and the processes followed to complete transfers. In both projects, the identification/selection of young prisoner interviewees was undertaken in close collaboration with nominated personnel in the institutions and conducted in line with institutional ethical approval and guidelines from the NOMS National Research Committee. To maintain ethical sensitivity to participants, information sheets were adapted to acknowledge the varying developmental needs of young people held; neither patronising nor too adult-centric. Where written consent was attained through gatekeepers, the interviewer later obtained verbal consent from young people to ensure that they were aware that they had the power over their decision making (Heath et al., 2009).

In both projects, audio recordings were transcribed and NVivo software was used to develop inductive nodes and codes. Prominent themes - such as regime, accommodation, staff relationships, and identity - were identified within each study and a rigorous strategy of reflection

\footnotetext{
2 Jayne Price's data comes from her PhD research 'exploring pathways and transitions between the juvenile secure estate and young adult/adult estate' conducted at the University of Liverpool, which was funded by the Economic and Social Research Council (ESRC) CASE studentship (ES/J500094/1) and received in kind contribution from HMI of Prisons. The primary data that was collected between April 2017 and March 2018. As the research was conducted in YOIs which only hold males, this research does not include the experiences of females.

${ }^{3}$ In total, 27 interviews were conducted with young people for this research. One participant was released before their post-transition interview could be conducted.
} 
and analysis meant that the categories were continually developed and refined (Searle, 2004). Upon collaborative reflection, it became clear that transitions across the wider Youth Justice Estate were of paramount importance to all participants. The findings presented in the next sections are a result of a further period of deductive coding conducted simultaneously by the co-authors to attend to childhood to adulthood 'transitions' across institutional settings. By combining findings from the two research projects, this paper presents the first concerted academic attempt to provide a broader snapshot of the experiences of children and young people in these various institutional spaces in conjunction with an analysis of adolescent development. There is increasing pressure within the policy-orientated research on criminal justice to ensure the credibility of data. Whilst quantitative approaches are often considered robust in terms of their ability to generate representations of a particular population, there is an intrinsic value to qualitative studies, albeit with lower numbers of participants. Given the small sample sizes, it is impossible for our data to be able to speak to all of the experiences of children and young people through the criminal justice system. Indeed, the omission of data from SCHs is of note here. Additionally, whilst this data presented here does not track individual biographies throughout the juvenile secure estate, the perspectives of those within STCs and from YOIs to young adult/adult institutions offers original insights into the experience of transitions within youth and young adult incarceration. What this paper can uniquely contribute is a set of discussions, derived from the voices of those who live and work in these spaces, that raises considerable debate about the nature of these transitionary experiences in a project that is the first of its kind to try to piece together stories from differentlygenerated information. In the remainder of the paper, we first reflect upon the experience of incarceration within a STC before moving onto analyse how young people negotiate transitions from YOIs into young adult/adult institutions.

\section{Training Children}

With the name of the institution emerging from a particular criminal sentence - the Secure Training Order (STO) - we argue that STCs connote a regime of development both in terms of transformative positive behaviour and a transition to adulthood. As previously discussed, incarcerated children are consistently considered to be 'vulnerable' due, in particular, to their status as 'minors'. Accordingly, custodial institutions responsible for housing this cohort have a significant duty of care towards them, which manifests most in its physical environment. Jones 
argues that the entry shock - 'the turmoil that individuals face during their initial period of incarceration when they [...] are cut off from the outside world' (2011:21) - can be far greater for young prisoners than the general, adult population. In that respect, STCs have been designed to reduce this shock. Although security is often an issue, with typically half of the children having violent offences on their records (Hagell et al, 2000: 39), vulnerability is often a prevailing consideration and results in alterations to the physical landscape. A double-layer mesh fence is substituted for the notorious prison wall and strong plastic coverings replace titanium bars on windows, features dominant in so many stereotypical images of custodial spaces, to reduce the austerity of the environment. The children (or 'trainees' as they were frequently known) are housed in much smaller living units (typically 5-8 persons) than in YOIs and the young adult/adult estate. Domestic-style kitchens and living areas on each unit are intended to promote a feeling of 'normality'. Although the windows in residential areas are generally inward-facing, the central space between the small clusters of buildings is often 'softened' by a lawn area.

Trainees had clearly built up expectations about what life in a secure setting was going to be like. Many recounted significant anxieties about personal safety and living conditions prior to entry:

I didn't even realise an STC or a YOI were a place. I thought you just go straight to a HMP and then possibly, get raped and stabbed. And then you come out and you think, what the hell just happened. I was actually hoping they were going to keep me in a police cell because I was afraid that much to come to a HMP (interview, STC trainee 1)

Some respondents relayed that they had expected to have to wear a 'blue prison uniform'. Their clear preconceptions about the environment and the staff were often contra their experience:

The first time I saw it, I didn't know it was going to be anything like this, I thought it was going to be harsher ... I thought it was going to be ... evil staff (interview, STC trainee 5)

I think everything was a lot better than what I expected it to be ... It made me feel a lot less anxious about being in prison ... because obviously it was unexpected, I 
didn't know what to expect, when I first got here, it was definitely a bit of a relief (interview, STC trainee 7)

Such impressions were paramount in reducing the anxieties of the trainees, notably in their first few moments inside a custodial space. It must be reiterated that, although responses indicated that the STC was 'better than expected', a certain opinion about the prevailing standards of accommodation for young prisoners was strongly expressed. When shown photographs of a UK adult prison cell, which contrasted significantly with their counterparts in the STC - minimal sanitation, barred windows and shared rooms, for example - children demonstrated a strong opinion of adult offenders being less deserving of 'nicer environments'. In the main, respondents indicated that it should be 'rougher for adults that it should be for kids' because adults 'should know better' and 'should be a lot more mature' (interview, STC trainee 2). Many other children provided similar responses, which adopted the age-determined constructs that institutions placed upon them: 'I think what we get given ... I know we're in jail but for our age it's bad' (focus group, STC young person, emphasis added). Here, the interviewee articulated that they understood that perceptions of adults are quite different, which is demonstrated in the environment in which they are held. Others exhibited knowledge of the wider custodial environment and demonstrated gratitude for the 'softer' environment they were incarcerated in:

I think I am quite mature for my age compared to other people, so I know how lucky you are to be sent here and how much better it is here than other places. I have been on visits to prisons and that and there is definitely a big difference here and I think a lot of people don't really realise that until they're sent to another place and ... by that point it's too late then. (interview, STC trainee 7)

Of particular focus is the space afforded to sleep. In the STC under study, this was an individual room, which was named (and referred to by those who lived in it) as a bedroom. The rooms in the STC under study were stark, but deliberately so. Each fixture and fitting has been carefully designed to eliminate ligature points and reduce the availability of items that children might find to harm themselves or others. Each bedroom also has its own attached bathing facilities and could be furnished with personal belongings in accordance with the individual's risk assessment. This is particularly pertinent for young prisoners in this environment, as several staff members explained, due to the high prevalence of sexual and physical abuse prior to incarceration. 
Although it may appear plausible that vulnerability would equate to a 'softer' custodial environment, this is often subsumed by the high levels of damage within institutions housing children, which render 'unbreakable' or 'institutional' fixtures and fittings necessary. An evaluation carried out at Medway STC in 2000 reported that, after opening, the children soon 'tested the fabric of the building to its limits and beyond' with damage described as including: 'destroyed beds, cupboard doors off their hinges, security cameras torn from their seating, windows smashed and graffiti'. As such, the environment required 'continual repair' (Hagell et al, 2000: 46). As one of our respondents explained: 'you've got to remember, these are teenage children who... [have] outbursts ... it's so volatile here, it can go within a second' (interview, STC staff member 2). It was suggested that '[y]oung people don't have the basics of right and wrong' (interview, STC staff member 2). Whilst staff members acknowledged the likelihood that those held have experienced social disadvantage, they overlooked the fact that such behaviour could be attributed to emotional distress and posited that children in this environment require 'training' into how to be respectful.

In terms of institutional regime, it was clear that some staff were willing to go above and beyond to generate positive relationships with children. The positive responses are here, notably, something at odds with the critical appraisals of STCs already published (Taylor 2016). Trainees commented that 'some staff will do stuff that they don't actually have to, but they will'. This might include 'making drinks' or 'getting along', which reportedly 'makes your time a little bit easier'. Staff reported a high level of pride in their occupations and exhibited great desires to improve the situations of those in their care. However, it was noted that some trainees were at the beginning of long custodial sentences, some of which would necessarily be spent in young adult/adult facilities. Staff were often worried about the stark level of contrast they would experience upon being transferred and often commented that the more personal or overly-friendly approach of some staff might exacerbate those transition issues:

[W]e have young people that ... They almost need coaxing into bed every night, and, "oh can you stand and talk to me for ten minutes before I go to sleep?" The staff are like, "of course we can", because that's part of their role and that's what they do. If one of those people went into a YOI and said that to a member of staff ... They'd say, "You need to go to your room", and they're like, "no!" they'd be like, "okay well you're going - I will take you". "Oh, can you stand and talk to me at my door for ten minutes?" "No, I can't - I'm 
going home." And that's not because they don't care, but it's not in their job description. They've got 90 other kids on that wing that they need to be looking after. They're not bothered whether you're happy, sad, want to talk about a bad phone call that you've had. Like I say it's not because they're bad at their job, it's not their job. The expectations in that sense are very different. (interview, STC staff member 9)

The transition between these spaces is not only felt in regime, but in size and style of the facility, which (as discussed later in this article) can be stark. Several of our respondents commented that it was vital that the changing demographic of those held required particular support for the change in treatment they would receive in a young adult/adult facility:

I think ... that we always need somewhere that supports young people with transition. So having a 17-year-old on a four-month order where they can spend eight weeks in here and eight weeks going back out into the community is very different to having what we have at the moment, where we have a 14-year-old on a 15-year sentence, where ultimately they're going to have to transition. It's a completely different level of planning. [They] need to be prepared. At the moment, there's lots of other stuff going on, but in the six months leading up to [them] being transferred there needs to be some sort of change in [their] expectations, so what's expected of [them], and that's about developing and supporting young people to mature. (interview, STC staff member 10)

In the following section of the paper, we further explore by comparison, the tensions of precisely this transition through custodial spaces, from STC to dedicated YOI institutions and incarceration as young adults in the adult estate.

\section{Managing young people}

Whilst units within YOIs are smaller than young adult/adult institutions, they are much larger than STCs with the capacity for up to 288 young people (up to 80 in an STC and 24 in SCH) (Brooks, et al., 2019). In anticipation of the transition to the young adult/adult estate, and in line with placement guidance (YJB, 2014 ${ }^{4}$ ), four of the young people interviewed in the second research

\footnotetext{
${ }^{4}$ Not all males will transition into a YOI from an STC. The guidance dictates that consideration should be made to the most beneficial option for the individual (YJB, 2018) although our analysis here disputes whether this is realised in practice.
} 
project research had transferred to a YOI from a STC. The MoJ (2012: 5) recognise the developmental differences between young people and adults and state that: 'every care should be taken to ensure that both the conditions of custody and regime activities promote their well-being and healthy growth.' Despite this, the environment within a YOI is more aligned to a prison than STCs and a young person reported that they were "terrible" in comparison (Casper, Pre-interview, YOI). To prepare them, a young person reported that their regime was adapted to mirror that within a YOI, particularly in relation to time spent outside of their immediate living space:

[...] it were just like spending less, like more time in room, less time out of it. (Christopher ${ }^{5}$, Pre-interview, YOI).

Upon arrival at the YOI, young people are 'booked in' at reception, which includes being searched and issued with prison clothing including jogging pants and a jumper (denoting the institution's initials). Only some young people interviewed were informed of the rules and the regime, yet all were advised by staff members to 'keep their head down' i.e. keep out of trouble. Reflecting on their feelings upon arrival, several participants reported concerns about personal safety:

[I felt] Scared, because you didn't know what was going to happen, you know, its jail, could get jumped, could get your stuff stolen, it's what my Dad did when he went, I just felt a little scared, nervous. (Niall, Pre-interview, YOI)

It is at this daunting point of arrival when young people are also asked by a stranger to disclose any mental health issues. The staff advice departs from the role those in STCs had with children and creates the expectation of violence, which does not produce an environment in which young people might feel comfortable expressing any concerns. Fractured relationships continued and one young person reported that he found the smaller units and greater staffing levels in STCs much more supportive:

I was on a unit with ten people and it was the same staff week in week out yeah they were the ones, I felt, if I could go back there I'd change everything to go back there because they

\footnotetext{
${ }^{5}$ All the young people interviewed in the second research project were given pseudonyms which are culturally similar to their names instead of participant numbers. This reflects the slight variance in the methodologies of the two wider research projects.
} 
like actually wanted to help you, but here, they just don't, they just care about getting their pay-check at the end of the month you know or causing a drama because they haven't got anything better to do. (Noah, Pre-interview, YOI)

The further detrimental impact of lower staffing levels upon transition is explored in the following section.

Whilst the young people interviewed in STCs acknowledged that the environment should account for their age, those in YOIs faced with the prospect of transition sought to demonstrate they were ready to progress through to another institution. Although aware of the significant removal of supportive provision, they believed that 'the greater levels of autonomy' (MoJ, 2013a: 14) they were expected to adapt to as adults would bring greater freedoms within their regime:

[I expect the young adult/adult estate would] [t]rust you with more, more things, there, you can dine out with everyone, you can mix with different wings, here, you can't do that. (Nabi, Pre-interview, YOI)

I'm excited for it like, can't wait to go, because, there's certain stuff I want to be able to do and you can't do here. I think it's better than being in here, because its more freedom and more relaxed, like here, I'm with loads of like boisterous 15-18-year olds. (Craig, Preinterview, YOI)

Staff reported that expectations were perhaps utopian:

[...] they think it's the holy grail moving to the 18-21 estate, they think it's an open pot of money, they can do this, they can do that, but at the end of the day they don't realise there it's short staff[ed], horrible facilities, but the only advantage is, they can wear their own clothes and they can smoke. (Staff member YOI, Interview 5)

Whilst, as much as possible, the young people wished to distance themselves from the notion of being a child because they associated this with being vulnerable and thus at risk of victimisation (Coyle, 2019), some had apprehensions about young adult/adult institutions. Several respondents reported expectations of fighting, drug-taking, and other 'drama' (Noah, Pre-Interview, YOI) intrinsically linked to the maturity of the age group entering the young adult/adult estate from a YOI background: 
[...] when I go into another jail, I have to prove myself again, like try and get the respect level, because all they see is a little 18-year-old who's just come from a YOI, like, these are all grown men like 30-odd year olds and that ... Like I don't know, don't know [how to prove myself] because, on one hand I just wanna calm down and that, on the other hand I don't want people to look at me like I'm an absolute idiot, I don't know, think I will end up fighting a bit. (Craig, Pre-interview, YOI)

The following section outlines the realities of this transition into the young adult/adult estate.

\section{Neglecting 'adults'}

The vast difference between facilities in the juvenile secure estate and the young adult/adult estate is evident in physical and operational features. Designated young adult YOIs hold around 600 people with some adult prisons having capacity for over 1,000. 'Cells' - as opposed to 'rooms' can be dual occupancy (although young adults should not share with anyone aged over 21 years) (NOMS, 2012). The physical differences between institutions can exacerbate the daunting experience of arrival:

I'm on a big wing... it's different [to Juvenile YOI] where there was 40 on the wing, now there's 90. You don't like, you just can't talk to the staff as much. (Kendrick, Postinterview, Young Adult/Adult Institution)

The operational differences also present challenges. In particular, young people recounted increased 'bang up' time (Kendrick, Post-Interview, Young Adult/Adult Institution) when the regime was limited or cancelled. Whilst there were concerns about staffing shortages in the juvenile YOIs, they were keenly felt in the young adult/adult estate. Respondents raised significant concerns about the wider effects upon this cohort of prisoners:

[...] you've not got enough officers for the vulnerable, traumatised young people, again you hear that, you know young people are having to stay in cells longer and not being allowed some of the basic human rights like exercise often, when they are in this situation where there are simply not enough officers to allow them out. (Academic, Interview 4) 
You're more likely in a young adult establishment, to find vulnerable prisoners locked up in grim conditions for long periods of time, and that not being addressed. So, rather than, at least in the juvenile estate they will know who those people are and they will try and do something, because there's enough people to notice and jiggle stuff around but, in the young adult's estate I think there's much more of a problem. (Inspector One, Interview 7)

Significant criticism was levelled at resources available. Monetary support in custodial institutions decreases as age increases and 'all of a sudden' upon transition (Staff member, YOI, Interview 6). Staff members were aware of the differences in treatment between establishments and acknowledged the paradox between developmental maturity as an individualistic ongoing process and arbitrary transitions:

[I]t's across the spectrum, it's like you can have an 18 year old that's really immature but you can have a 16 year old that ... [...] I think it depends on what kind of background they come from, and life experiences as well, some lads who come here might be really street wise but in other things they're not. (Staff member, YOI Interview 3)

One staff member indicated that the 'onus' was 'all of a sudden' placed upon the young people (Staff member, Young Adult/Adult Institution, Interview 16), in stark contrast to the juvenile secure estate. Whilst some young people had previously commented that they wished for greater autonomy, the shift in staff attitudes between institutions and dearth of support is problematic. Stakeholders were critical of the impacts of imprisonment and inadequate support upon young adults' well-being during this crucial period. Such sentiment echoes HM Chief Inspector of Prisons' (2015) view that these institutions have a bearing upon the maturation of the individuals housed within them:

Certainly young people within the custodial environment, [it] is bound to slow down the maturation process significantly as it takes away responsibility, you don't make decisions, it's a very odd kind of environment in which to grow up. (Academic Two Interview 8).

Young adults are expected to take responsibility for their behaviours whilst they are still developing neurologically, which affects their ability to do so. Whilst those aged 18-20 years are defined as 'young adults', the distinction in categorisation appears to offer little other provision or support. The distinct drop in staffing levels and shift of responsibility is further evidence of the 
detrimental impact of lower investment for support offered to young people subject to arbitrary transitions through institutions, which is discussed further in the following section.

\section{Conclusion}

Within this paper the terminology used when referring to those experiencing transitions between institutions purposefully shifted from children to young people. This is how those interviewed described themselves and was deliberately employed to demonstrate the "essential point that child prisoners appear to lose their status as children when they enter the very 'adult' prison environment' (Gooch, 2015: 5). It is reflective of some subtle changes - i.e. language moving from training centre to institution and from bedroom to cell - and other starker changes - i.e. distinct drop in staffing provision - that take place in the transition from STCs to YOIs, as well as the contradictory constructions of those held. Whilst STCs have received criticism, the evidence here indicates that they offer comparatively more resources and staff seek to support; 'human potential of youth as route towards progress or improvement' (Lesko, 2012: 164). This appears to diminish within YOIs and there is ultimately a 'cliff-edge' (The Children's Society, 2019) of support within young adult/adult institutions with progressively fewer physical safeguards, more time in cell, lesser activity and a reduction in staffing levels and, therefore, vital interactions.

Young prisoners move between environments with different ideas of responsibility. Whilst STCs are focused on safeguards and support accounting for the particular needs of children, YOIs appear to view those held 'as subjects in need of external control and discipline' (Bottrell and Armstrong, 2007: 369). This persists into the young adult/adult estate as they are expected to be more autonomous, cope with fewer resources and therefore become more responsible for their own needs and vulnerability despite ongoing neurological development. Whilst (NOMS, 2015) acknowledge the importance of support for young adults with identity formation, self-sufficiency and responsibility, it does not deliver in practice. The experiences of young people and perspectives of stakeholders here demonstrate how YOIs and young adult/adult institutions do not lend themselves to the period of adolescence development and heightened sensitivity to such negative stimuli (Tanner and Arnett, 2009; Brewster, 2019).In contrast, our findings indicate that, rather than being child-centred and acknowledging the implications of developmental maturity, YOIs and young adult/adult institutions are too focused on 'a retaliatory response to crime, thus failing to treat offending children as wayward and in need of a guiding hand' (Gillen, 2006: 139). 
In exploring these institutions comparatively, we must recognise that this construction is, of course, a relative appraisal and that we do not wish to underplay the previous assessments that critique various aspects of the STC institution as a discrete part of the criminal justice landscape (see Taylor 2016).

As discussed within the introduction, adolescent development is individualistic and ongoing, and wider societal transitions are extended. However, for those in institutions, transitions are arbitrarily set and therefore much more rigid, 'precarious' and 'hazardous' (Goldson, 2019: 242). The complex neurological development of young adults is typically viewed negatively due to the irrational and anti-social responses they can exhibit (Bessant, 2008). Those held in custody are likely to be functioning at a lower level of maturity yet receive decreasing support, and as Brewster (2019: 12) has argued, young adults are not adequately developed to 'deal' with adult systems". However our evidence highlights that such spaces are instead not structured in a way to 'deal' with young adults appropriately and appreciate their capacity for development. As the interview data demonstrates, entering a new environment can be 'bewildering' (Brewster, 2019) and difficult to navigate. From entry to YOIs, staff members - whether purposefully or not created a 'culture of fear' (de Viggiani, 2018) and the young people felt that they must prove themselves and distance themselves from any notion of vulnerability. This in turn lends itself to an environment fuelled with violence and poorer outcomes for young adults.

Whilst plans are in place to develop the juvenile secure estate (MoJ, 2016) the 'distinct' young adult estate continues to be absorbed within the adult estate (HM Chief Inspector of Prisons, 2015) and the category of 'young adults' defined as age 18-20 appears to offer little distinction in practice. The drop in provision demonstrates the 'second rate' status of young adults (Scott and Grisso, 1997; Bryan-Hancock and Casey, 2011). There is broad-based acknowledgement that lifestage transitions occur later (Roberts, 2009; Livingstone et al., 2015; House of Commons Justice Committee, 2016; Goldson, 2019) and the requirement for developmentally-appropriate support for young people within the CJS has seemingly been acknowledged in Government discourse (MoJ, 2015b, 2016, 2017). However, as this paper demonstrates, it is not evident in operational practices. Notwithstanding the conundrum that age boundaries do offer clear opportunities to maintain important aspects of child protection and safeguarding, the focus on age is reductionist (James and James, 2004). It conceals neurological development (Edwards, 2009), inequalities and 
individual differences (Woodman and Wyn, 2013). Rather than the current arbitrary removal of support, we argue here for a more developmental approach to physical structures and operational practices, which provides ongoing individually focused, tailored support that is more appropriate for those held within and transitioning between spaces of youth and young adult custody. Such support must meet the challenge of ensuring that the wider benefits of age-specific treatment such as the safeguarding of minors - are flexible enough to meet the demands of young people with variable adolescent development. To achieve this, a significant investment in resources and specialist training that recognises the distinct needs of young people as they progress through the system is required (House of Commons Justice Committee, 2016). Unless realised, the effects of incarceration will continue to exacerbate the harms upon an already vulnerable and marginalised cohort of society.

Whilst extending the remit of the YJB to young adult has been dismissed - due to broader complications that might arise from this approach - there have been calls for continuation of support through institutions and a distinct approach that recognises the impacts of developmental maturity upon young adults individual needs, behaviours and ongoing identity formation (House of Commons Justice Committee, 2016; NOMS, 2015). The evidence presented in this paper supports the argument that institutions for young adults should be authentically distinct from adult prisons, cater for young adults (to be defined as up to age 25 years) and adequately supported with sufficient staff members who have received appropriate training to understand how to engage effectively with young adults (Harris, 2015; House of Commons Justice Committee, 2016). The young people interviewed here desired a sense of autonomy over their circumstances, which has

been encouraged for their developing capacity (Bessant, 2008), but this must be tailored to avoid the 'cliff-edge' of supportive services and loss of adequate regime from age 18 years. Young adults should be provided with an environment, regime and provision similar to that within the juvenile secure estate, which recognises their complex life-stage and nurtures ongoing neurological development in order to facilitate positive outcomes.

\section{References}

Abrams, L., Anderson-Nathe, B. and Aguilar, J. (2008). Constructing masculinities in juvenile corrections. Men and Masculinities, 11(1):22-41. 
Article39.org.uk. (2020). Serious safety warnings - child prisons.

https://article39.org.uk/2020/01/11/serious-safety-warnings-child-prisons/.

Bateman, T. (2012). Who pulled the plug? Towards an explanation of the fall in child imprisonment in England and Wales. Youth Justice, 12(1):36-52.

Bateman, T. (2015). Resettlement of young people leaving custody: Lessons from the literature: Update March 2015. Beyond Youth Custody. http://www.beyondyouthcustody.net/wpcontent/uploads/Resettlement-of-young-people-leaving-custody-lessons-from-theliterature-March-2015.pdf.

Bessant, J. (2008) Hard wired for risk: neurological science, 'the adolescent brain' and developmental theory, Journal of Youth Studies, 11:3, 347-360.

Bottrell, D. and Armstrong, D. (2007). Changes and exchanges in marginal youth transitions, Journal of Youth Studies, 10(3):353-371.

Brooks, S., Johnson, P., Clarke, S. and Morton, L. (2019). Youth Custody Service Safeguarding Review. UK: The Stationary Office.

Brewster, D. (2019). Not Wired Up? The Neuroscientific Turn in Youth to Adult (Y2A) Transitions Policy. Youth Justice https://doi.org/10.1177/1473225419876458

Bryan-Hancock, C. and Casey, S. (2011). Young people and the Justice System: consideration of maturity in criminal justice responsibility. Psychiatry, psychology and Law, 18(1):6978.

Clarke, P. (2019, July, 22). [Urgent notification: HMYOI Feltham A] Her Majesty's Chief Inspector of Prisons. London: United Kingdom.

Coyle, B. (2019). 'What the $\mathrm{f}^{* *} \mathrm{k}$ is maturity?': Young adulthood, subjective maturity and desistance from crime, British Journal of Criminology, 57(5):1178-1198.

De Viggiani, N. (2018). "Don't mess with me!" Enacting masculinities under a compulsory prison regime. In M. Maycock, and K. Hunt, (eds.), New Perspectives on Prison Masculinities (pp. 91-121). London: Palgrave McMillan. 
Department for Education. (2020). Children Accommodated in Secure Children's Homes at $31^{\text {st }}$ March 2019: England and Wales. London: Department for Education.

Dünkel, F. (2015). Juvenile justice and crime policy in Europe. In F. Zimring, M. Langer and D. D. Tannenhaus, (eds.). Juvenile Justice in Global Perspective (pp. 9-62). New York: New York University Press.

Edwards, T. (2009). Capacity and the Adolescent Brain, Psychiatry, Psychology and Law, 16(3):427-434.

Elwood, C. (2013). Children and Young People in Custody 2012-13: An Analysis of 12-18 YearOlds' Perceptions of Their Experience in Secure Training Centres. HM Inspectorate of Prisons and Youth Justice Board: Norwich.

Falola, S. (2020). FOI Request - 200414006. [personal correspondence].

Gillen, J. (2006). The age of criminal responsibility: "the frontier between care and justice", Child care in practice, 12(2):129-139.

Goldson, B. (2002). Vulnerable Inside: Children in Secure and Penal Settings. London: The Children's Society.

Goldson, B. (2005). Child imprisonment: A case for abolition. Youth Justice 5(2):77-90.

Goldson, B. (2013). “'Unsafe, unjust and harmful to wider society': grounds for raising the minimum age of criminal responsibility in England and Wales', Youth Justice, 13(2):111130.

Goldson, B. (2015). The circular motions of penal politics and the pervasive irrationalities of child imprisonment. In B. Goldson., and J. Muncie (eds.). Youth Crime and Justice (pp. 170-190). London: Sage.

Goldson, B. (2019). Reading the present and mapping the future(s) of juvenile justice in Europe: complexities and challenges. In B. Goldson, (ed.). Juvenile Justice in Europe: Past, Present and Future (pp. 209-253). Oxon: Routledge. 
Gooch, K. (2015). Who needs restraining? Re-examining the use of physical restraint in an English young offender institution, Journal of Social Welfare and Family Law, 37(1):320.

Gooch, K. (2016). A childhood cut short: child deaths in penal custody and the pains of child imprisonment, The Howard Journal of Crime and Justice, 55(3):278-294.

Gooch, K. (2019). 'Kidulthood': Ethnography, juvenile prison violence and the transition from 'boys' to 'men', Criminology and Criminal Justice, 19(1):80-97.

Green, L. (2019). Children in Custody 2017-18: An Analysis of 12-18 year olds' Perceptions of their Experience in Secure Training Centres and Young Offender Institutions. London: Her Majesty's Inspectorate of Prisons and Youth Justice Board.

Hagell, A., Hazel, N. and Shaw, C. (2000). Evaluation of Medway Secure Training Centre. Home Office: London.

Harris, T. (2015). Changing prisons, saving lives: Report of the independent review into selfinflicted deaths in custody of 18-24 year olds, (Cm 9087) July, 2015. London: Home Office.

Hart, D. (2017). The 'transformation' of youth custody: a discussion paper National Association for Youth Justice May 2017. http://thenayj.org.uk/wp-content/uploads/2017/05/NAYJBriefing-Transformation-of-Youth-Custody-May17.pdf.

Heath, S., Brooks, R., Cleaver, E. and Ireland, E. (2009). Researching young people's lives. London: Sage.

Heinz, W. (2009). Youth transitions in an age of uncertainty in A. Furlong, (ed.) Handbook of youth and young adulthood, (pp. 3-13). Oxon: Routledge.

Her Majesty's Chief Inspector of Prisons. (2015). Written evidence from Her Majesty's Chief Inspector of Prisons House of Commons Justice Committee Inquiry into Young Adult Offenders. London: Her Majesty's Inspectorate of Prisons.

Her Majesty’s Chief Inspector of Prisons. (2017). Annual report 2016-17 (HC 208) London: Her Majesty's Chief Inspectorate of Prisons. 
Her Majesty's Inspectorate of Prisons. (2000). Unjust Deserts: A Thematic Review by HM Chief Inspector of Prisons of the Treatment and Conditions for Unsentenced Prisoners in England and Wales. Her Majesty's Inspectorate of Prisons for England and Wales: London.

Her Majesty's Inspectorate of Prisons and Her Majesty's Inspectorate of Probation. (2019). Joint Thematic Inspection by HM Inspectorate of Probation and HM Inspectorate of Prisons: Youth resettlement work. Interim report into work in custody October 2018 - April 2019.

House of Commons Justice Committee. (2016). The treatment of young adults in the criminal justice system. Seventh Report of Session 2016-17 (HC 169). London: The Stationary Office. http://www.publications.parliament.uk/pa/cm201617/cmselect/cmjust/169/169.pdf.

Hughes, N. and Strong, G. (2016). Implementing the evidence on young adult neuromaturation: the development of a specialist approach in probation services, Probation Journal, $63(4): 452-459$.

Independent Inquiry Child Sexual Abuse. (2019). Sexual abuse of children in custodial institutions 2009-2017 Investigation report February 2019. Independent Inquiry Child Sexual Abuse.

James, A and James, A. (2004). Constructing childhood: theory, policy and social research. New York: Palgrave Macmillan.

Jones, H. (2011). The pains of custody: Young men's experiences of pre-prison custodial settings. Prison Service Journal 197: 20-25.

Kroll, L., Rothwell, J., Bradley, D., Shah, P., Bailey, S. and Harrington, R.C. (2002). Mental health needs of boys in secure care for serious or persistent offending: A prospective, longitudinal study. The Lancet 359(9322):1975-1979.

Lesko, N. (2012). Act your age: a cultural construction of adolescence ( $2^{\text {nd }}$ ed.). Florence: Routledge. 
Livingstone, I, Amad, S. and Clark, L. (2015). Effective approaches to working with young adults: a guide for probation services. London: Transition to Adulthood. http://www.t2a.org.uk/wp-content/uploads/2015/10/Probation-guide_Web-Ver4.pdf.

Ministry of Justice (MoJ). (2012). PSI 08/2012 Care and management of young people. London: National Offender Management Service.

Ministry of Justice (MoJ). (2013a). Transforming Management of Young Adults in Custody (CM 8733). London: The Stationary Office.

Ministry of Justice (MoJ). (2015a). Women Prisoners. London: Ministry of Justice. https://www.justicegov.uk/offenders/types-of-offender/women.

Ministry of Justice (MoJ) (2015b). Government response to the Harris Review into self-inflicted deaths in National Offender Management Service custody of 18-24 year olds. London: The Stationary Office.

Ministry of Justice (MoJ). (2016). The government's response to Charlie Taylor's review of the Youth Justice System. London: The Stationary Office.

Ministry of Justice (MoJ). (2017). Government Response to the Justice Committee's Seventh Report of Session 2016-17: The treatment of young adults in the criminal justice system. London: Ministry of Justice

Ministry of Justice, HM Prison Service \& Her Majesty's Prison and Probation Service. (2020). Prison population figures: 2019: Population bulletin: monthly December 2019. [data set].

National Audit Office. (2010). The Youth Justice System in England and Wales: Reducing Offending by Young People. Report by the Comptroller and Auditor General. HC 633 Session 2010-2011. National Audit Office: London.

National Offender Management Service. (2012). The transition process: guidance on transfers from under 18 young offender institutions to young adult Young Offender Institutions. London: Ministry of Justice and National Offender Management Service. 
National Offender Management Service. (2015). Better outcomes for young adult men. London: National Offender Management Service.

National Preventative Mechanism (NPM). (2018). Monitoring places of detention: eighth annual report of the United Kingdom's National Preventative Mechanism 1 April 2016-31 March 2017 CM9563.

Panorama. (2016). Teenage prison abuse exposed [TV] BBC Monday $11^{\text {th }}$ January 2016. 20:30.

Roberts, K. (2009). Youth in transition: Eastern Europe and the West. England: Palgrave Macmillan.

Sawyer, S., Azzopardi, P., Wickremarathne, D. and Patton, G. (2018). The age of adolescence, The Lancet: Child and Adolescent Health, 2(3): 223-228.

Scott, E.S. and Grisso, T. (1997). The evolution of adolescence: a developmental perspective on juvenile justice reform, Journal of Criminal Law and Criminology, 88(1):137-189.

Searle, C. (2004). Generating grounded theory. In C. Searle (ed.) Researching Society and Culture (pp. 240-247). London: Sage.

Tanner, J. and Arnett, J. (2009). The emergence of 'emerging adulthood' the new life stage between adolescence and young adulthood. In A. Furlong (ed.) Handbook of Youth and Young Adulthood (pp. 39-46). Oxon: Routledge.

The Children's Society. (2019). Transitions to adulthood: the case for a cross-departmental taskforce. The Children's Society, Coram Children's Legal Centre, Prince's Trust, National Children's Bureau, Safer London, Standing Committee for Youth Justice, Centrepoint, Parents Against Child Exploitation, Mencap, Child Poverty Action Group, Youth Action, Children and Young People's Mental Health Coalition and Association of Colleges.

Taylor, C. (2016). Review of the Youth Justice System in England and Wales. London: Her Majesty's Stationary Office. 
Walther, A. (2006). Regimes of youth transitions: choice, flexibility and security in young people's experiences across different European contexts, Young: Nordic Journal of Youth Research, 14(2):119-139.

Warner, L., Hales, H., Smith, J. and Bartlett, A. (2018). Secure settings for young people: a national scoping exercise. St George's University of London and NHS Central and North West London. https://www.england.nhs.uk/wp-content/uploads/2018/10/secure-settingsfor-young-people-a-national-scoping-exercise-paper-1-scoping-analysis.pdf.

Willow, C. (2015). Children behind bars: why the abuse of child imprisonment must end Bristol: Policy Press.

Wood, A. Bailey, S. and Butler, R. (2017). Findings and Recommendations of the Youth Custody Improvement Board. London: Youth Custody Improvement Board.

Woodman, D. and Wyn, J. (2013). Youth Policy and Generations: Why Youth Policy Needs to 'Rethink Youth', Social policy and society, 12(2):265-275.

Wyn, J. and White, R. (1997). Rethinking youth. Australia: Allen and Urwin.

Wyn, J. and Woodman, D. (2006). Generation, Youth and Social Change in Australia, Journal of Youth Studies, 9(5):495-514.

Youth Justice Board (YJB). (2011). Strategy for the Secure Estate for Children and Young People in England and Wales. Plans for 2011/12 - 2014/15. Consultation Document. Youth Justice Board: London.

Youth Justice Board (YJB). (2014). Placement review process. London: Youth Justice Board and Youth Custody Service.

Youth Justice Board (YJB). (2018). Joint National Protocol for Transitions in England: Joint protocol for managing the cases of young people moving from Youth Offending Teams to Probation Services. London: Youth Justice Board, Her Majesty's Prison and Probation Service and National Probation Service.

Youth Justice Board (2020a). Youth justice statistics: 2018-19. London: Youth Justice Board. 
Youth Justice Board (2020b). Youth justice statistics: 2018-2019 supplementary tables. Chapter 7: children in youth custody. [data set]. London: Youth Justice Board. 